\title{
Efficacy of intravesical pentosan polysulfate sodium in cats with obstructive feline idiopathic cystitis
}

Journal of Feline Medicine and Surgery 2016, Vol. 18(6) 492-500

(C) ISFM and AAFP 2015

Reprints and permissions:

sagepub.co.uk/journalsPermissions.nav DOI: $10.1177 / 1098612 \times 15588934$ jfms.com

\author{
Mareike Delille, Laura Fröhlich, Ralf S Müller, \\ Katrin Hartmann and Roswitha Dorsch
}

\begin{abstract}
Objectives Obstructive feline idiopathic cystitis is a common emergency in small animal practice. There is evidence for a defective glycosaminoglycan layer in the urinary bladder of affected cats. The aim of this study was to investigate the effect of intravesical pentosan polysulfate sodium (PPS) in cats with obstructive feline idiopathic cystitis in a randomised, placebo-controlled, blinded clinical study.

Methods Thirty-five cats with obstructive feline idiopathic cystitis were enrolled into the study. On day 0 , cats were randomised to receive either $30 \mathrm{mg}$ PPS in saline (18 cats) or saline alone as placebo (17 cats) at the time of indwelling urinary catheter placement and then after 24 and $48 \mathrm{~h}$. The catheter was clamped for $30 \mathrm{mins}$ after administration before connecting it to a sterile urine collection system. The procedure was repeated after 24 and $48 \mathrm{~h}$, and then the indwelling catheter was removed. Treatment success was assessed via the incidence of recurrent urethral obstruction, results of a scoring system for physical examination and daily urinalysis from day 0 to 5.

Results Recurrent urethral obstruction occurred in 3/18 cats of the verum group and 3/17 of the placebo group $(P=1.000)$. The verum group showed a significantly lower degree of microscopic haematuria between day 5 and day $0(P \leqslant 0.05)$. The placebo group showed a significantly lower degree of dipstick haematuria between day 5 and day 0 ( $P \leqslant 0.05)$. There was no difference in the clinical score between the groups in the investigated time period. Conclusions and relevance Intravesical instillation of PPS three times within $48 \mathrm{~h}$ in the chosen dose had no influence on the incidence of recurrent urethral obstruction and clinical signs in cats with obstructive feline idiopathic cystitis.
\end{abstract}

Accepted: 6 May 2015

\section{Introduction}

Feline idiopathic cystitis (FIC) is a common condition in cats presented at small animal clinics, and is characterised as sterile inflammation of the bladder in absence of a known cause. ${ }^{1}$ The aetiology of FIC is most likely multifactorial. ${ }^{2}$ Supporting a defect in the natural glycosaminoglycan (GAG) layer of the urothelium as a contributing factor are the significantly decreased urine GAG/creatinine ratios in cats with FIC compared with normal cats. ${ }^{3}$ The surface of the bladder mucosa is lined by GAGs ${ }^{4}$ and proteoglycans.5,6 GAGs are mucopolysaccharide chains built of unbranched polysaccharide molecules. ${ }^{7}$ Their major function is to prevent the adhesion of noxious substances (microbes, microcrystals, protein, ions, carcinogens and toxic waste products of metabolism) to the bladder wall. 4,8,9 Therefore, a defect GAG layer leads to increased exposure of the urothelium to noxious substances. In addition, epithelial defects and decreased transepithelial resistance have been identified in cats with FIC. ${ }^{10}$ These alterations can allow potentially harmful substances of the urine access to the lamina propria, resulting in chronic immune-mediated or neurogenic inflammation, mast cell activation and C-fibre stimulation in the submucosa. ${ }^{11}$ A defective GAG layer in the urinary bladder has been associated with interstitial cystitis (IC) in humans as well. ${ }^{12-14}$

Clinic for Small Animal Internal Medicine, LMU University of Munich, Germany

\section{Corresponding author:}

Roswitha Dorsch Dr med vet, DECVIM-CA (Internal Medicine), Ludwig-Maximilians-Universität München, Medizinische Kleintierklinik, Veterinärstr. 13, 80539 München, Germany

Email: roswitha.dorsch@Imu.de 
The most common clinical signs of FIC are a combination of haematuria, pollakiuria and periuria, as well as stranguria and dysuria.,12 Urethral obstruction (UO) in FIC can occur due to inflammation and spasms, or formation of a matrix-crystalline plug, which is mostly seen in male cats because of their long and narrow urethra. ${ }^{11,15,16} \mathrm{UO}$ is a life-threatening emergency ${ }^{17}$ and expensive to manage. Recurrent urethral obstruction $(\mathrm{rUO})$ is a major problem in affected cats. The proportion of cats with rUO varies from $22 \%$ to $58 \%$ of affected cats ${ }^{18-20}$ within an observation period of up to 6 months. The high recurrence rate often leads to frustration and even euthanasia. Long-term follow-up of male cats with obstructive lower urinary tract disease (LUTD) revealed that $21 \%$ of the patients were euthanased because od rUO. ${ }^{18}$ It is therefore essential to find treatments that reduce the high rate of $\mathrm{rUO}$, ease the pain and accelerate the healing process.

Pentosan polysulfate sodium (PPS) is a semi-synthetic sulfated proteoglycan similar in function and structure to heparin and GAG. ${ }^{21}$ PPS is supposed to replace damaged or missing parts in the endogenous GAG layer of the bladder wall. ${ }^{21,22}$ In humans, PPS has been proven to be safe, and intravesical instillation induced significant improvement of clinical signs in a placebo-controlled clinical study in women with IC. ${ }^{22,23}$ In cats, neither adverse nor beneficial effects were seen after oral ${ }^{24}$ and subcutaneous ${ }^{25}$ administration of PPS. In a recently performed pilot study in which cats were treated intravesically with a high dose of a solution containing hyaluronic acid (HA), chondroitin sulfate (CS) and N-acetyl-D glucosamine, statistically significant differences were not observed between the groups regarding $\mathrm{rUO}$ and pain score. ${ }^{26}$

The hypothesis of the present study was that repeated intravesical instillation of PPS would help to reduce inflammation in the urinary bladder and accelerate regeneration and restitution of the urothelium. This should also lead to a more rapid healing process and lower rates of rUOs by inflammatory products, leukocytes and erythrocytes.

\section{Material and methods}

\section{Study design}

The study had a prospective randomised, placebocontrolled, double-blind design. All cats were treated at the Clinic of Small Animal Medicine, LMU, Munich, from June 2011 to June 2014. The study was approved by the Government of Upper Bavaria (reference number 55.2-154-2532-8-12). Written informed consent was obtained from all owners before including their cats in the study.

\section{Patients}

All of the cats presenting with obstructive LUTD during this time period were screened for study eligibility. FIC was diagnosed by exclusion of other diseases of the lower urinary tract. Initial diagnostic investigations included a complete urinalysis (urine specific gravity [Reichert Vet 360]), urine dipstick (Combur 9 Test, Roche Diagnostics $\mathrm{GmbH}$ ), urine sediment, aerobic urine culture, as well as abdominal radiographs visualising the complete urethra and abdominal ultrasound. A complete blood count, serum chemistry profile and venous blood gas were performed on admission day (day 0) and repeated on day 1 and 2 if changes were observed on day 0 or 1 , respectively. Total thyroxine was measured in all cats older than 8 years of age, and all cats were tested for feline immunodeficiency virus (FIV) and feline leukaemia virus (FeLV), if the status was unknown. Cats were excluded if urolithiasis or severe crystalluria were identified, if structural abnormalities were observed on ultrasound, or if neurological deficits were noted on physical examination. Cats were also excluded if other diseases, such as chronic kidney disease, diabetes mellitus or hyperthyroidism, were identified, or if they had been treated with steroids, antimicrobial drugs or GAGs within the past 14 days. Any bacterial growth on urine samples obtained by cystocentesis on admission led to retrospective exclusion of affected cats (Figure 1).

\section{Randomisation and study medication}

A total of 52 cats were initially screened for enrolment into the study. Eight cats were excluded before randomisation. The remaining 44 cats were randomly assigned to either the verum group (22 cats) or the placebo group (22 cats; Figure 1). Randomisation was conducted by rolling a dice. Numbers 1,3 and 5 were assigned to group A, and numbers 2, 4 and 6 to group B. Study medications were drawn up by the clinical pharmacist. Verum and placebo were not distinguishable and were instilled by the treating veterinarian. Neither the veterinarian nor the owner was aware to which group the cat had been assigned. After the study was completed, all of the patients were decoded and data entered for statistical evaluation.

All of the cats received intravenous fluids and buprenorphine, and as soon as they were clinically stable, an indwelling urinary catheter (silicon feeding tube, $\mathrm{CH} 4.5,1.0 \mathrm{~mm} \times 1.5 \mathrm{~mm}$, Braun) was placed aseptically under anaesthesia. The urinary bladder was completely drained and flushed with warm sterile solution of sodium chloride until the urine appeared macroscopically clear. The study medication $(30 \mathrm{mg}$ PPS $=0.3 \mathrm{ml}$ [Pentosanpolysulfat SP $54100 \mathrm{mg}$ ] Injektionslösung, bene Arzneimittel $\mathrm{GmbH}$ ) in $10 \mathrm{ml}$ sterile solution of sodium chloride (verum) or placebo $(10 \mathrm{ml}$ sterile solution of sodium chloride, $0.9 \%$ ) was instilled into the urinary bladder via the urinary catheter. After administration, the catheter was clamped for $30 \mathrm{mins}$ before 


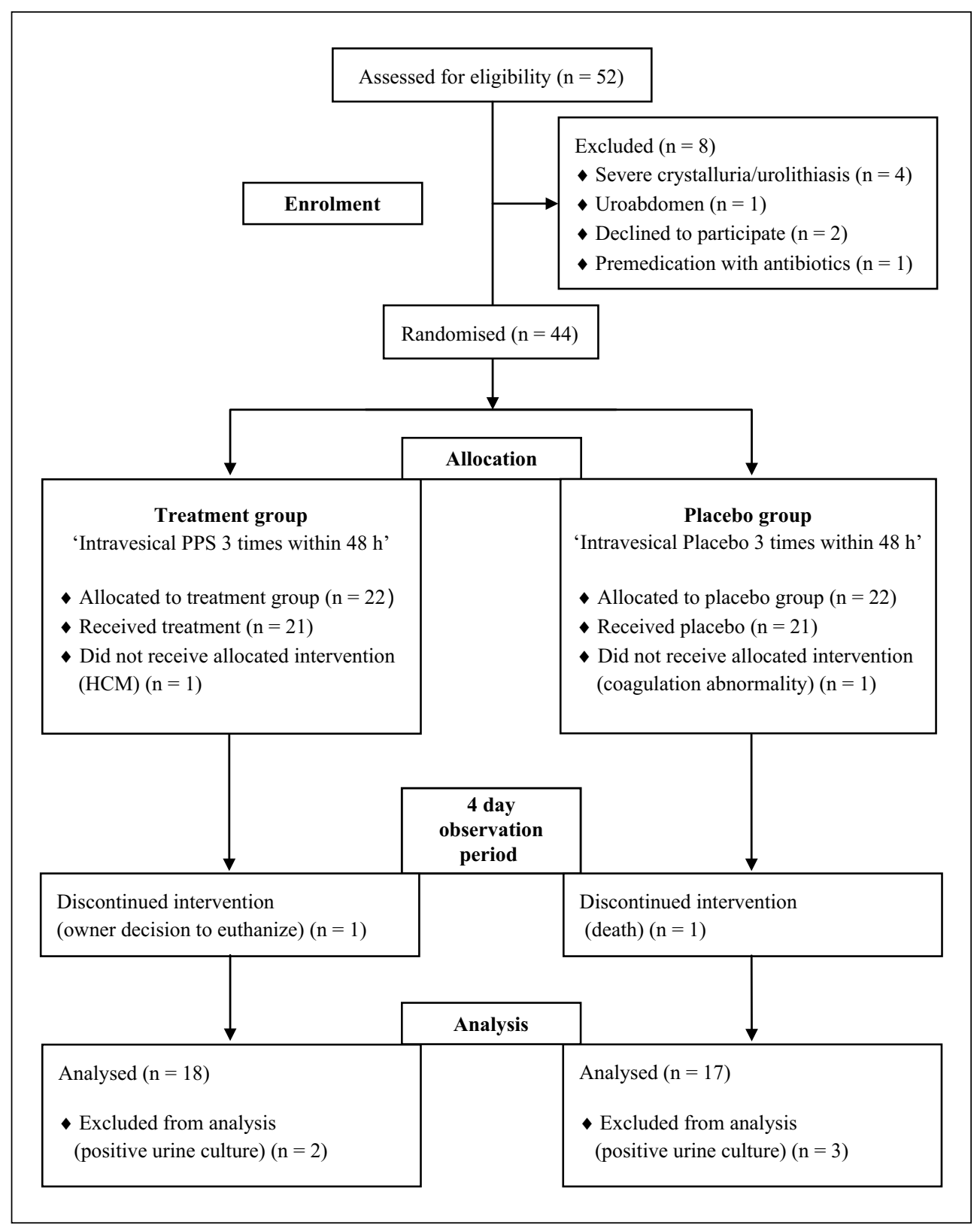

Figure 1 Flow chart of progress through phases of trial

connection to a sterile urine collection system. The assigned drug was repeatedly administered after 24 and $48 \mathrm{~h}$. The urine collection bag was placed well below the cat to avoid reflux of urine. The urinary catheter was removed after $48 \mathrm{~h}$. A new catheter was placed for another $24 \mathrm{~h}$ if cats did not urinate within $8 \mathrm{~h}$ after removing the first urinary catheter despite showing voiding attempts.

In addition to intravenous fluids, a treatment protocol used by Cooper et al $^{27}$ was adapted and applied during the hospitalisation period (Table 1).

During hospitalisation, all cats were offered a canned urinary diet in addition to what they were used to eating at home. A definitive diet change, measures to increase water intake and multimodal environmental modification were planned as long-term therapy at home.

\section{Urinalysis}

Urine samples were collected by transcutaneous cystocentesis on day 0 , and catheter-derived on days 1 and 2 . Urine samples were submitted for aerobic culture on days 0 and 2 . Voided urine samples - collected by Katkor (Non Absorb Cat Litter) - were used for analysis on days 3, 4 and 5 in cats without rUO $(n=29)$, and catheter derived samples were used if cats suffered from $\mathrm{rUO}(\mathrm{n}=6)$. Urinalysis (dipstick, USG, sediment) was always performed within 30mins 
Table 1 Supportive therapy used in the study in cats in both groups

\begin{tabular}{|c|c|c|}
\hline Drug & Dosage & $\begin{array}{l}\text { Day of } \\
\text { treatment }\end{array}$ \\
\hline Buprenorphine* & $0.01 \mathrm{mg} / \mathrm{kg}$ IV q8h & $0-5$ \\
\hline Phenoxybenzamine $^{\dagger}$ & $0.5 \mathrm{mg} / \mathrm{kg} P O \mathrm{q} 24 \mathrm{~h}$ & $3-14$ \\
\hline Acepromazine $\ddagger$ & $0.05 \mathrm{mg} / \mathrm{kg}$ IV q8h-q12h & $1-2$ \\
\hline
\end{tabular}

*Vetergesic, Ecuphar GmbH

tDibenzyran 5, Aristo Pharma GmbH

\#Vetranquil 1\%, Albrecht GmbH

after sampling. Urine was centrifuged at 2000 revolutions per min (rpm) for 5 mins. Twenty high-power fields (hpf; 400fold amplification) of the unstained urine sediment were investigated microscopically (Table 2).

\section{Evaluation of treatment success}

The main parameter for treatment success was the recurrence of UO and need for repeated catheterisation. The results of daily physical examinations and urinalyses were compared within the groups (day 0 with day 1, 2, 3, 4 and 5) and between groups on each day (0-5). In addition, a clinical score including parameters of urinalysis and the physical examination was developed (Table 2 and 3) and calculated daily. Each of the included parameters was graded according to severity from 0 to 4 for urinalysis results and from 0 to 3 for physical examination findings (Tables 2 and 3). Comparison of scores within treatment groups between individual days and comparison of scores between treatment groups on each day were performed. The highest score possible was 29 points per day.

\section{Statistical analysis}

GraphPad Prism 5 (v5.04 for Windows, 2010) was used for statistical analysis. Data were investigated for normal distribution using the Kolmogorov-Smirnov test and D'Agostino and Pearson omnibus normality test. The Kruskal-Wallis test and Dunn's multiple comparisons test were used for comparisons of continuous variables within groups and between groups at different time points. The Mann-Whitney U-test was used for comparison of continuous variables between groups at entry into the study. For evaluation of categorical data, the $\chi^{2}$ test was performed. Values of $P \leqslant 0.05$ were considered significant.

\section{Results}

There was no significant difference between cats of the PPS and the placebo group regarding signalment (Table 4), physical examination findings (Table 5) and laboratory parameters (Table 6) evaluated on admission.

UO recurred within the 4-day observation period after removal of the urinary catheter in three cats of the
PPS group (16.7\%) on days 3, 4 and 5, and in three placebo-treated cats $(17.6 \%)$ on days 2,3 and $4(P=1.000)$. Both groups showed a general amelioration in general demeanour, pain on abdominal palpation and appetite, with the greatest improvement from day 0 to day 1 . Differences between the two groups were not observed at any time point (Table 7).

Within both treatment groups, results of urinalysis improved over time. However, differences between groups were not observed on any day. The degree of microscopic haematuria was significantly lower in the verum group on day 5 compared with day $0(P \leqslant 0.05$; Table 7). Proteinuria was significantly lower in the verum group on day 4 compared with day $0(P \leqslant 0.05)$. Dipstick haematuria was significantly lower in the placebo group on day 5 compared with day $0(P \leqslant 0.05)$. Proteinuria was significantly lower in the placebo group on day $2(P \leqslant 0.05)$ and $3(P \leqslant 0.01)$ compared with day 0 (Table 7).

The clinical score decreased throughout the investigation period in both treatment groups without significant differences between groups at any time point.

\section{Discussion}

In this study, the effect of intravesically administered PPS in cats with obstructive FIC was investigated. PPS is a heparin-like semi-synthetic sulfated polysaccharide that resembles endogenous GAGs. ${ }^{28}$ The exact mechanism of PPS is not yet known. One widely accepted hypothesis is that PPS repairs missing parts in the damaged GAG layer. ${ }^{21}$ PPS is a common oral medication in the management of IC in humans, ${ }^{29}$ and oral treatment with PPS over a 32-week period induced clinical improvement that paralleled improvement of intravesical potassium sensitivity tests, indicating decreased permeability of the bladder epithelium after treatment with PPS. ${ }^{30}$ In addition, PPS has anticoagulatory and fibrinolytic properties. ${ }^{28,31}$ In vitro, PPS has been shown to inhibit nuclear factor- $\kappa \mathrm{B}$ (activated by chronic inflammatory diseases) and consequently to reduce inflammation of the bladder mucosa. ${ }^{32}$ Two additional in vitro studies reported an inhibition of mast cell stimulation by PPS that resulted in a reduction of histamine secretion. ${ }^{33,34}$ Long-term oral supplementation of PPS (6-8 months) in women with IC appears to reduce pain (42-62\%) and urgency (35-56\%) successfully. ${ }^{29,35,36}$ Various studies demonstrated that PPS is more efficacious than placebo in the treatment of IC associated pain, urgency and frequency. ${ }^{21,37,38}$ However, there are still patients with unsatisfactory responses to treatment. A possible reason for this might be that no more than $6 \%$ of the orally administered dose is excreted via urine. ${ }^{39}$ Therefore, intravesical administration in addition to oral PPS was investigated in IC patients. The addition of intravesically administered PPS resulted in a significant improvement 
Table 2 Scoring system for urine parameters according to severity

\begin{tabular}{|c|c|c|c|c|c|}
\hline Parameter & Grade 0 & Grade 1 & Grade 2 & Grade 3 & Grade 4 \\
\hline Haematuria, dipstick & Negative & $1+$ & $2+$ & $3+$ & $4+$ \\
\hline Proteinuria, dipstick & Negative & $1+$ & $2+$ & $3+$ & $4+$ \\
\hline Erythrocytes/hpf & $0-4$ & $5-15$ & $16-50$ & $51-100$ & $>100$ \\
\hline Leukocytes/hpf & Negative & $0-5$ & $6-12$ & $13-19$ & $>20$ \\
\hline Macroscopic haematuria & Negative & & Positive & & \\
\hline Urine cloudy/flakes & Negative & Positive & & & \\
\hline
\end{tabular}

hpf = high-power field

Table 3 Scoring system for clinical parameters according to severity

\begin{tabular}{|c|c|c|c|c|}
\hline Parameter & Grade 0 & Grade 1 & Grade 2 & Grade 3 \\
\hline General demeanour & Normal & Mildly depressed & Moderately depressed & Severely depressed \\
\hline Appetite & Normal & Mildly decreased & Moderately decreased & Severely decreased \\
\hline Size of bladder & Normal & Mildly enlarged & Moderately enlarged & Severely enlarged \\
\hline $\begin{array}{l}\text { Abdominal pain } \\
\text { on palpation }\end{array}$ & None & Slightly painful & Moderately painful & Severely painful \\
\hline
\end{tabular}

Table 4 Signalment of cats in the pentosan polysulfate sodium (PPS) group and placebo group on admission

\begin{tabular}{|c|c|c|c|}
\hline Parameter & $\operatorname{PPS}(n=18)$ & Placebo $(n=17)$ & $P$ value \\
\hline Sex, male & $\begin{array}{l}\text { Intact }(n=3) \\
\text { Neutered }(n=15)\end{array}$ & $\begin{array}{l}\text { Intact }(n=3) \\
\text { Neutered }(n=14)\end{array}$ & $0.939^{*}$ \\
\hline Breed & $\begin{array}{l}\text { DSH }(n=12) \\
\text { Purebred }(n=6) \\
\text { (3 Persian, } 3 \text { Carthusian) }\end{array}$ & $\begin{array}{l}\text { DSH }(n=14) \\
\text { Purebred }(n=3) \\
\text { (1 Persian, } 2 \text { Carthusian) }\end{array}$ & $0.515^{\star}$ \\
\hline Episodes & $\begin{array}{l}\text { 1st }(n=12) \\
\text { 2nd }(n=6)\end{array}$ & $\begin{array}{l}\text { 1st }(n=12) \\
\text { 2nd }(n=6)\end{array}$ & $0.521^{*}$ \\
\hline $\begin{array}{l}\text { Age in years, median } \\
\text { (range) }\end{array}$ & $6.4(2-10.5)$ & $5(1-15)$ & $0.582^{\dagger}$ \\
\hline $\begin{array}{l}\text { Body weight in } \mathrm{kg} \text {, } \\
\text { median (range) }\end{array}$ & $5.85(4.5-8.3)$ & $5.8(3.8-7.1)$ & $0.438^{\dagger}$ \\
\hline $\begin{array}{l}\text { Body condition score, } \\
\text { median (range) }\end{array}$ & $6 / 9(4 / 9-9 / 9)$ & $6 / 9(5 / 9-8 / 9)$ & $0.107^{\star}$ \\
\hline
\end{tabular}

in the severity of clinical signs compared with the control group that were only treated orally. ${ }^{22}$ Adverse effects were uncommon in humans but can consist of diarrhoea, nausea, alopecia and headache. $28,35,36,40,41$

In cats, PPS administered subcutaneously ${ }^{25}$ for 5 days or orally for 6 months ${ }^{42}$ did not result in significant differences in clinical signs and recurrence rates compared with the control groups. Oral administration of N-acetyl-Dglucosamine for a period of 6 months did not show any effect in cats with FIC either. ${ }^{24}$ The present study investigated the hypothesis that intravesical instillation of PPS in cats might provide a beneficial approach in treating cats with obstructive FIC. However, in this study, the response of the cats to intravesically administered PPS was not of any clinical benefit. Possible reasons for the lack of efficacy could be the dose, the dosage and the residence time of PPS in the urinary bladder in this study. The dose used in the present study ( $30 \mathrm{mg}$ per cat) was extrapolated from human medicine, as women receive an instillation of 200-300 mg per session.22,23 This dose might not have been adequate for instillation in cats, and a higher concentration in the urinary bladder could produce greater effects. In addition, all of the cats enrolled in the present study were obstructed, whereas UO is only a rare feature in 
Table 5 Initial physical examination of the cats in the pentosan polysulfate sodium (PPS) group and placebo group

\begin{tabular}{|c|c|c|c|c|}
\hline Parameter & & $\operatorname{PPS}(n=18)$ & Placebo $(n=17)$ & $P$ value \\
\hline \multirow[t]{4}{*}{ General condition } & NAD & 0 & 3 & \multirow[t]{4}{*}{$0.068^{*}$} \\
\hline & Minor & 11 & 4 & \\
\hline & Moderate & 6 & 4 & \\
\hline & Profound & 1 & 6 & \\
\hline Temperature & ${ }^{\circ} \mathrm{C}$, mean $\pm \mathrm{SD}$ & $38.07 \pm 1.18$ & $38.03 \pm 0.99$ & $0.999^{\dagger}$ \\
\hline Heart rate & Per minute, mean $\pm S D$ & $186.17 \pm 33.75$ & $172.06 \pm 30.13$ & $0.289^{\dagger}$ \\
\hline Respiratory rate & Per minute, mean $\pm S D$ & $37.62 \pm 26.17$ & $47.93 \pm 31.60$ & $0.311^{\dagger}$ \\
\hline \multirow[t]{4}{*}{ Abdominal pain on palpation } & NAD & 0 & 0 & \multirow[t]{4}{*}{$0.089^{*}$} \\
\hline & Minor & 2 & 2 & \\
\hline & Moderate & 6 & 6 & \\
\hline & Profound & 10 & 9 & \\
\hline
\end{tabular}

${ }^{*} \chi^{2}$ test

†Mann-Whitney U-test

$\mathrm{NAD}=$ no abnormalities detected

Table 6 Concentration of blood urea nitrogen (BUN), creatinine (CREA) and potassium of the pentosan polysulfate sodium (PPS) group and placebo group on admission

$\begin{array}{lcccc}\text { Parameter } & \text { PPS }(n=18) & \text { Placebo }(n=17) & \text { Reference interval } & P \text { value } \\ \begin{array}{l}\text { BUN mmol/l, } \\ \text { mean } \pm \text { SD }\end{array} & 34.83 \pm 29.51 & 31.08 \pm 36.53 & 5-11.3 & 0.228^{*} \\ \begin{array}{l}\text { CREA } \mu \mathrm{mol} / \mathrm{l}, \\ \text { mean } \pm \mathrm{SD}\end{array} & 585.81 \pm 652.39 & 550.23 \pm 686.03 & 0-169 & 0.563^{*} \\ \begin{array}{l}\text { Potassium mmol/l, } \\ \text { mean } \pm \mathrm{SD}^{*}\end{array} & 5.24 \pm 2.13 & 4.95 \pm 2.21 & 3.5-5.6 & 0.775^{*}\end{array}$

*Mann-Whitney U-test

women with IC..$^{37,38}$ Post-obstructive diuresis is a common feature after relief of UO. ${ }^{43}$ Thus, diuresis could have led to a dilution of the medication in the urinary bladder and inadequate PPS concentrations in the urine. Potentially higher doses of PPS compensating for the dilution in postobstructive diuresis might be beneficial. Another approach could be to increase the frequency of PPS instillation (eg, q12h within 2 days) or a longer duration of catheterisation with more frequent instillations of the medication. This may result in a more continuous supplementation of exogenous GAGs to the bladder wall. One disadvantage of such an approach is the higher incidence of catheterassociated bacterial infection accompanying extended treatment with indwelling urinary catheters. ${ }^{4}$

In IC, women are advised to hold the instilled medication for 30 mins. $^{22}$ Therefore, the indwelling urinary catheter was clamped for the same amount of time. Extending the residence time of PPS may permit the instilled drug additional time to take an effect. However, this prolonged iatrogenic obstruction might increase pressure in the urinary bladder which may cause more discomfort for the cat.

The urothelial GAG layer is a combination of mainly heparan sulfate and CS and minor components, such as HA, dermatan sulfate and keratan sulfate. A combination of different GAGs (CS, HA and N-acetyl-glucosamine) in high concentrations was administered intravesically to cats with obstructive FIC in a recently published placebocontrolled pilot study. In this study, the main parameter assessed to determine treatment success was the occurrence of rUO. None of the seven cats in the treatment group and three of nine cats $(3 / 9,33.3 \%)$ in the placebo group showed rUO. Although the results were not statistically significant, the need is noted for further investigation with a larger study group. ${ }^{26}$

In the present study, the rates of rUO in the PPS and placebo group ( $16.7 \%$ and $17.6 \%$, respectively) were lower than previously reported with recurrence rates of $58 \%$ within 3 days and $36 \%$ within 17 days, 18,20 whereas other studies observed a recurrence rate of $15 \%$ (observation period of 2 months) in cats with UO of any cause and $22 \%$ (observation period of 6 months) in cats with obstructive FIC. 19,45 Variable inclusion criteria (FIC and UO of any cause), study designs (prospective and retrospective), as well as a different medical management (eg, use of $\alpha$-sympatholytic drugs or no $\alpha$-sympatholytic drugs) and follow-up periods could have influenced the different rates of rUO. The generally low recurrence rate of the present study population might have obscured the beneficial effects 
Table 7 Score for clinical and laboratory parameters in cats receiving pentosan polysulfate sodium (PPS) and placebo treatments, including the mean values, standard deviations and $P$ values of the changes over time within each group (day 0 vs 1 , day 0 vs 2 , day 0 vs 3 , day 0 vs 4 , day 0 vs 5 ) and comparisons of groups on days $0,1,2,3,4$ and 5

\begin{tabular}{|c|c|c|c|c|c|c|c|c|}
\hline \multirow[t]{2}{*}{ Variable } & \multirow[t]{2}{*}{ Day } & \multicolumn{2}{|c|}{$\begin{array}{l}\text { Number of collected } \\
\text { data }\end{array}$} & \multirow[t]{2}{*}{$\begin{array}{l}\text { Mean } \pm \text { SD } \\
\text { PPS }\end{array}$} & \multirow[t]{2}{*}{$\begin{array}{l}\text { Mean } \pm \text { SD } \\
\text { placebo }\end{array}$} & \multirow{2}{*}{$\begin{array}{l}P \text { value }^{*} \\
\text { PPS vs } \\
\text { placebo }\end{array}$} & \multirow{2}{*}{$\begin{array}{l}P \text { value }{ }^{\star} \text { day } \\
0 \text { vs } 1,2,3 \text {, } \\
4,5 \text { PPS }\end{array}$} & \multirow{2}{*}{$\begin{array}{l}P \text { value }{ }^{*} \text { day } \\
0 \text { vs } 1,2,3, \\
4,5 \text { placebo }\end{array}$} \\
\hline & & PPS & Placebo & & & & & \\
\hline \multirow{6}{*}{$\begin{array}{l}\text { General } \\
\text { condition } \\
\text { (grade 0-3) }\end{array}$} & 0 & 18 & 17 & $1.23 \pm 0.77$ & $1.76 \pm 1.15$ & ns & & \\
\hline & 1 & 17 & 17 & $0.75 \pm 0.44$ & $0.58 \pm 0.71$ & ns & ns & $\leqslant 0.05$ \\
\hline & 2 & 15 & 16 & $0.53 \pm 0.52$ & $0.50 \pm 0.82$ & ns & $\leqslant 0.05$ & $\leqslant 0.01$ \\
\hline & 3 & 15 & 16 & $0.40 \pm 0.51$ & $0.56 \pm 0.63$ & ns & $\leqslant 0.01$ & $\leqslant 0.05$ \\
\hline & 4 & 12 & 13 & $0.33 \pm 0.49$ & $0.54 \pm 0.66$ & ns & $\leqslant 0.001$ & $\leqslant 0.05$ \\
\hline & 5 & 12 & 10 & $0.16 \pm 0.39$ & $0.20 \pm 0.42$ & ns & $\leqslant 0.001$ & $\leqslant 0.001$ \\
\hline \multirow{6}{*}{$\begin{array}{l}\text { Appetite } \\
\text { (grade 0-3) }\end{array}$} & 0 & 17 & 17 & $1.81 \pm 1.32$ & $1.58 \pm 1.33$ & ns & & \\
\hline & 1 & 16 & 14 & $1.80 \pm 1.45$ & $1.50 \pm 1.45$ & ns & ns & ns \\
\hline & 2 & 15 & 15 & $1.20 \pm 1.26$ & $1.33 \pm 1.05$ & ns & ns & ns \\
\hline & 3 & 15 & 16 & $0.60 \pm 0.98$ & $1.06 \pm 1.06$ & ns & $\leqslant 0.05$ & ns \\
\hline & 4 & 12 & 12 & $1.16 \pm 1.40$ & $0.58 \pm 0.99$ & ns & ns & ns \\
\hline & 5 & 12 & 10 & $0.16 \pm 0.39$ & $0.40 \pm 0.84$ & ns & $\leqslant 0.01$ & ns \\
\hline \multirow{4}{*}{$\begin{array}{l}\text { Size of bladder } \\
\text { (grade 0-3) }\end{array}$} & 0 & 16 & 17 & $2.40 \pm 0.63$ & $2.47 \pm 0.62$ & ns & & \\
\hline & 3 & 12 & 15 & $1.25 \pm 0.87$ & $1.13 \pm 0.74$ & ns & $\leqslant 0.01$ & $\leqslant 0.001$ \\
\hline & 4 & 11 & 13 & $1.35 \pm 1.21$ & $1.00 \pm 1.00$ & ns & $\leqslant 0.05$ & $\leqslant 0.001$ \\
\hline & 5 & 11 & 10 & $0.73 \pm 0.79$ & $1.00 \pm 0.94$ & ns & $\leqslant 0.001$ & $\leqslant 0.001$ \\
\hline \multirow{6}{*}{$\begin{array}{l}\text { Pain on } \\
\text { abdominal } \\
\text { palpation } \\
\text { (grade 0-3) }\end{array}$} & 0 & 17 & 17 & $2.44 \pm 0.72$ & $2.41 \pm 0.71$ & ns & & \\
\hline & 1 & 15 & 17 & $1.27 \pm 0.70$ & $1.18 \pm 0.88$ & ns & $\leqslant 0.01$ & $\leqslant 0.01$ \\
\hline & 2 & 14 & 16 & $0.86 \pm 0.77$ & $0.88 \pm 0.71$ & ns & $\leqslant 0.001$ & $\leqslant 0.001$ \\
\hline & 3 & 14 & 16 & $1.14 \pm 0.77$ & $0.94 \pm 0.77$ & ns & $\leqslant 0.01$ & $\leqslant 0.001$ \\
\hline & 4 & 11 & 13 & $1.00 \pm 1.00$ & $0.77 \pm 0.73$ & ns & $\leqslant 0.001$ & $\leqslant 0.001$ \\
\hline & 5 & 11 & 10 & $0.64 \pm 0.50$ & $0.80 \pm 0.63$ & ns & $\leqslant 0.001$ & $\leqslant 0.001$ \\
\hline \multirow{6}{*}{$\begin{array}{l}\text { Haematuria, } \\
\text { dipstick } \\
\text { (grade 1-4) }\end{array}$} & 0 & 17 & 16 & $3.88 \pm 0.49$ & $3.94 \pm 0.25$ & ns & & \\
\hline & 1 & 17 & 16 & $3.38 \pm 0.94$ & $3.81 \pm 0.54$ & ns & ns & ns \\
\hline & 2 & 16 & 14 & $3.47 \pm 1.10$ & $3.64 \pm 0.93$ & ns & ns & ns \\
\hline & 3 & 16 & 13 & $3.33 \pm 1.03$ & $3.54 \pm 0.88$ & ns & ns & ns \\
\hline & 4 & 9 & 12 & $2.88 \pm 1.32$ & $2.83 \pm 1.47$ & ns & ns & ns \\
\hline & 5 & 11 & 10 & $3.30 \pm 1.21$ & $2.90 \pm 1.29$ & ns & ns & $\leqslant 0.05$ \\
\hline \multirow{6}{*}{$\begin{array}{l}\text { Proteinuria, } \\
\text { dipstick } \\
\text { (grade 1-4) }\end{array}$} & 0 & 18 & 17 & $2.71 \pm 0.84$ & $2.41 \pm 0.71$ & ns & & \\
\hline & 1 & 15 & 16 & $2.64 \pm 0.99$ & $2.38 \pm 0.72$ & ns & ns & ns \\
\hline & 2 & 13 & 15 & $2.25 \pm 1.07$ & $1.47 \pm 0.74$ & ns & ns & $\leqslant 0.05$ \\
\hline & 3 & 11 & 12 & $2.20 \pm 0.87$ & $1.33 \pm 0.65$ & ns & ns & $\leqslant 0.01$ \\
\hline & 4 & 9 & 11 & $1.87 \pm 0.83$ & $1.91 \pm 1.04$ & ns & $\leqslant 0.05$ & ns \\
\hline & 5 & 13 & 12 & $1.83 \pm 0.93$ & $2.00 \pm 0.95$ & ns & ns & ns \\
\hline \multirow{6}{*}{$\begin{array}{l}\text { Erythrocytes/ } \\
\text { hpf } \\
\text { (grade 1-4) }\end{array}$} & 0 & 17 & 17 & $2.53 \pm 0.81$ & $2.47 \pm 0.79$ & ns & & \\
\hline & 1 & 17 & 17 & $2.25 \pm 1.10$ & $2.47 \pm 0.63$ & ns & ns & ns \\
\hline & 2 & 18 & 15 & $2.06 \pm 1.09$ & $2.07 \pm 1.09$ & ns & ns & ns \\
\hline & 3 & 17 & 15 & $1.71 \pm 0.96$ & $2.47 \pm 0.83$ & ns & ns & ns \\
\hline & 4 & 13 & 11 & $1.60 \pm 1.12$ & $1.91 \pm 1.30$ & ns & ns & ns \\
\hline & 5 & 13 & 10 & $1.50 \pm 0.97$ & $1.60 \pm 1.07$ & ns & $\leqslant 0.05$ & ns \\
\hline \multirow{6}{*}{$\begin{array}{l}\text { Leukocytes/hpf } \\
\text { (grade 1-4) }\end{array}$} & 0 & 16 & 16 & $1.13 \pm 0.54$ & $1.31 \pm 0.87$ & ns & & \\
\hline & 1 & 16 & 17 & $1.40 \pm 0.73$ & $1.24 \pm 0.83$ & ns & ns & ns \\
\hline & 2 & 16 & 15 & $1.33 \pm 0.60$ & $1.47 \pm 0.92$ & ns & ns & ns \\
\hline & 3 & 15 & 15 & $1.29 \pm 0.82$ & $1.20 \pm 0.94$ & ns & ns & ns \\
\hline & 4 & 11 & 12 & $1.50 \pm 1.04$ & $1.33 \pm 0.89$ & ns & ns & ns \\
\hline & 5 & 13 & 10 & $1.33 \pm 0.77$ & $1.20 \pm 1.03$ & ns & ns & ns \\
\hline
\end{tabular}


Table 7 (Continued)

\begin{tabular}{|c|c|c|c|c|c|c|c|c|}
\hline \multirow[t]{2}{*}{ Variable } & \multirow[t]{2}{*}{ Day } & \multicolumn{2}{|c|}{$\begin{array}{l}\text { Number of collected } \\
\text { data }\end{array}$} & \multirow[t]{2}{*}{$\begin{array}{l}\text { Mean } \pm S D \\
\text { PPS }\end{array}$} & \multirow[t]{2}{*}{$\begin{array}{l}\text { Mean } \pm \text { SD } \\
\text { placebo }\end{array}$} & \multirow{2}{*}{$\begin{array}{l}P \text { value* } \\
\text { PPS vs } \\
\text { placebo }\end{array}$} & \multirow{2}{*}{$\begin{array}{l}P \text { value }{ }^{\star} \text { day } \\
0 \text { vs } 1,2,3, \\
4,5 \text { PPS }\end{array}$} & \multirow{2}{*}{$\begin{array}{l}P \text { value }{ }^{*} \text { day } \\
0 \text { vs } 1,2,3, \\
4,5 \text { placebo }\end{array}$} \\
\hline & & PPS & Placebo & & & & & \\
\hline \multirow{6}{*}{$\begin{array}{l}\text { Score } \\
\text { (highest } \\
\text { possible } \\
\text { points: 29) }\end{array}$} & 0 & 18 & 17 & $18.94 \pm 5.26$ & $19.00 \pm 4.47$ & $\mathrm{~ns}$ & & \\
\hline & 1 & 18 & 17 & $13.94 \pm 5.39$ & $14.94 \pm 3.94$ & $\mathrm{~ns}$ & ns & ns \\
\hline & 2 & 17 & 16 & $12.06 \pm 3.78$ & $12.44 \pm 4.18$ & ns & $\leqslant 0.01$ & $\leqslant 0.01$ \\
\hline & 3 & 16 & 16 & $11.31 \pm 3.48$ & $11.63 \pm 4.75$ & ns & $\leqslant 0.01$ & $\leqslant 0.01$ \\
\hline & 4 & 13 & 13 & $9.85 \pm 5.13$ & $10.38 \pm 5.95$ & ns & $\leqslant 0.001$ & $\leqslant 0.001$ \\
\hline & 5 & 13 & 12 & $9.31 \pm 4.11$ & $9.25 \pm 5.36$ & ns & $\leqslant 0.001$ & $\leqslant 0.001$ \\
\hline
\end{tabular}

*Kruskal-Wallis test and Dunn's multiple comparisons test ns = not significant; $\mathrm{hpf}=$ high-power field

of PPS, with rUO being the main parameter used to assess treatment success. The risk of mechanical injury to the urinary tract and incidence of bacterial infection have been reported to increase with the duration of catheterisation. Catheterisation in the current study was limited to 2 days (48h). ${ }^{44}$ A retrospective study showed that a duration of catheterisation $>26 \mathrm{~h}$ may be associated with a lower probability of short-term $\mathrm{rUO}^{45}$ which may have caused the relatively low rate of $\mathrm{rUO}$ in the present study.

In all of the cats included in the present study, haematuria and proteinuria decreased significantly, which is expected with bladder irrigation and drainage. The improvement in haematuria in the placebo group was only observed in the dipstick evaluation, whereas in the PPS group, there was a significant improvement of microscopic haematuria. Counting cells in microscopic analysis is more sensitive than dipstick evaluation, which can show colour changes in the presence of not just intact erythrocytes, but also haemoglobin and myoglobin. In this study, there was only a small difference with regard to absolute numbers of haematuria and proteinuria of the PPS and the placebo group between days. Although statistically significant, these results probably are not clinically relevant.

The limitations of this study include the small sample size and inability to collect samples from all of cats at all time points. Consequently, comparisons between the groups suffered from a low statistical power and were prone to type II errors. Secondly, retrograde urethrography or urethroscopy was not performed in these patients. Therefore, strictures of the urethra and radiolucent urethroliths may have been missed.

\section{Conclusions}

This study was not able to show that repeated intravesical instillation of PPS three times within $48 \mathrm{~h}$ into the urinary bladder has any apparent beneficial effect on decreasing the recurrence rate of $\mathrm{UO}$, as well as clinical signs in cats with obstructive FIC. No adverse effects of intravesical PPS administration were observed.
Acknowledgements We wish to thank Norbert Klaus for his support in preparing the study medications of this study.

Funding This research received no specific grant from any funding agency in the public, commercial or not-for-profit sectors.

Conflict of interest The authors do not have any potential conflicts of interest to declare.

\section{References}

1 Westropp JL and Tony Buffington CA. Feline idiopathic cystitis: current understanding of pathophysiology and management. Vet Clin North Am Small Anim Pract 2004; 34: 1043-1055.

2 Buffington CA. Idiopathic cystitis in domestic cats beyond the lower urinary tract. J Vet Intern Med 2011; 25: 784-796.

3 Panchaphanpong J, Asawakarn T and Pusoonthornthum R. Effects of oral administration of $\mathrm{N}$-acetyl-D-glucosamine on plasma and urine concentrations of glycosaminoglycans in cats with idiopathic cystitis. Am J Vet Res 2011; 72: 843-850.

4 Hostutler RA, Chew DJ and DiBartola SP. Recent concepts in feline lower urinary tract disease. Vet Clin North Am Small Anim Pract 2005; 35: 147-170.

5 Hurst RE and Zebrowski R. Identification of proteoglycans present at high density on bovine and human bladder luminal surface. J Urol 1994; 152: 1641-1645.

6 Hurst RE. Structure, function, and pathology of proteoglycans and glycosaminoglycans in the urinary tract. World J Urol 1994; 12: 3-10.

7 Pereira DA, Aguiar JA, Hagiwara MK, et al. Changes in cat urinary glycosaminoglycans with age and in feline urologic syndrome. Biochim Biophys Acta 2004; 1672: 1-11.

8 Parsons CL, Boychuk D, Jones S, et al. Bladder surface glycosaminoglycans: an epithelial permeability barrier. J Urol 1990; 143: 139-142.

9 Parsons CL, Greenspan C, Moore SW, et al. Role of surface mucin in primary antibacterial defense of bladder. Urology 1977; 9: 48-52.

10 Lavelle JP, Meyers SA, Ruiz WG, et al. Urothelial pathophysiological changes in feline interstitial cystitis: a human model. Am J Physiol Renal Physiol 2000; 278: F540-553. 
11 Kruger JM, Osborne CA and Lulich JP. Changing paradigms of feline idiopathic cystitis. Vet Clin North Am Small Anim Pract 2009; 39: 15-40.

12 Buffington CA, Chew DJ and DiBartola SP. Interstitial cystitis in cats. Vet Clin North Am Small Anim Pract 1996; 26: 317-326.

13 Hurst RE, Roy JB, Min KW, et al. A deficit of chondroitin sulfate proteoglycans on the bladder uroepithelium in interstitial cystitis. Urology 1996; 48: 817-821.

14 Parsons CL, Lilly JD and Stein P. Epithelial dysfunction in nonbacterial cystitis (interstitial cystitis). J Urol 1991; 145: 732-735.

15 Defauw PA, Van de Maele I, Duchateau L, et al. Risk factors and clinical presentation of cats with feline idiopathic cystitis. J Feline Med Surg 2011; 13: 967-975.

16 Willeberg P. Epidemiology of naturally occurring feline urologic syndrome. Vet Clin North Am Small Anim Pract 1984; 14: 455-469.

17 Osborne CA, Kruger JM, Lulich JP, et al. Medical management of feline urethral obstruction. Vet Clin North Am Small Anim Pract 1996; 26: 483-498.

18 Gerber B, Eichenberger S and Reusch CE. Guarded longterm prognosis in male cats with urethral obstruction. J Feline Med Surg 2008; 10: 16-23.

19 Segev G, Livne H, Ranen E, et al. Urethral obstruction in cats: predisposing factors, clinical, clinicopathological characteristics and prognosis. J Feline Med Surg 2011; 13: 101-108.

20 Zezza L, Reusch CE and Gerber B. Intravesical application of lidocaine and sodium bicarbonate in the treatment of obstructive idiopathic lower urinary tract disease in cats. J Vet Intern Med 2012; 26: 526-531.

21 Anderson VR and Perry CM. Pentosan polysulfate: a review of its use in the relief of bladder pain or discomfort in interstitial cystitis. Drugs 2006; 66: 821-835.

22 Davis EL, El Khoudary SR, Talbott EO, et al. Safety and efficacy of the use of intravesical and oral pentosan polysulfate sodium for interstitial cystitis: a randomized double-blind clinical trial. J Urol 2008; 179: 177-185.

23 BadeJJ, Laseur M, Nieuwenburg A, et al. A placebo-controlled study of intravesical pentosanpolysulphate for the treatment of interstitial cystitis. Br J Urol 1997; 79: 168-171.

24 Gunn-Moore DA and Shenoy CM. Oral glucosamine and the management of feline idiopathic cystitis. J Feline Med Surg 2004; 6: 219-225.

25 Wallius BM and Tidholm AE. Use of pentosan polysulphate in cats with idiopathic, non-obstructive lower urinary tract disease: a double-blind, randomised, placebo-controlled trial. J Feline Med Surg 2009; 11: 409-412.

26 Bradley AM and Lappin MR. Intravesical glycosaminoglycans for obstructive feline idiopathic cystitis: a pilot study. J Feline Med Surg 2013; 16: 504-506.

27 Cooper ES, Owens TJ, Chew DJ, et al. A protocol for managing urethral obstruction in male cats without urethral catheterization. J Am Vet Med Assoc 2010; 237: 1261-1266.

28 Janssen Pharmaceuticals. Elmiron (pentosan polysulfate sodium) $100 \mathrm{mg}$ capsules. http://www.orthoelmiron. com/ (2012, accessed Feburary 25, 2015).
29 Nickel JC, Barkin J, Forrest J, et al. Randomized, double-blind, dose-ranging study of pentosan polysulfate sodium for interstitial cystitis. Urology 2005; 65: 654-658.

30 Parsons CL, Forrest J, Nickel JC, et al. Effect of pentosan polysulfate therapy on intravesical potassium sensitivity. Urology 2002; 59: 329-333.

31 Volpi N. Therapeutic applications of glycosaminoglycans. Curr Med Chem 2006; 13: 1799-1810.

32 Sadhukhan PC, Tchetgen MB, Rackley RR, et al. Sodium pentosan polysulfate reduces urothelial responses to inflammatory stimuli via an indirect mechanism. J Urol 2002; 168: 289-292.

33 Chiang G, Patra P, Letourneau R, et al. Pentosanpolysulfate inhibits mast cell histamine secretion and intracellular calcium ion levels: an alternative explanation of its beneficial effect in interstitial cystitis. J Urol 2000; 164: 2119-2125.

34 Chiang G, Patra P, Letourneau R, et al. Pentosanpolysulfate (Elmiron) is a potent inhibitor of mast cell histamine secretion. Adv Exp Med Biol 2003; 539: 713-729.

35 Hanno PM. Analysis of long-term Elmiron therapy for interstitial cystitis. Urol Clin North Am 1997; 49: 93-99.

36 Jepsen JV, Sall M, Rhodes PR, et al. Long-term experience with pentosanpolysulfate in interstitial cystitis. Urology 1998; 51: 381-387.

37 Hwang P, Auclair B, Beechinor D, et al. Efficacy of pentosan polysulfate in the treatment of interstitial cystitis: a meta-analysis. Urol Clin North Am 1997; 50: 39-43.

38 Parsons CL. Current strategies for managing interstitial cystitis. Expert Opin Pharmacother 2004; 5: 287-293.

39 Simon M, McClanahan RH, Shah JF, et al. Metabolism of [3H]pentosan polysulfate sodium (PPS) in healthy human volunteers. Xenobiotica 2005; 35: 775-784.

40 Mulholland SG, Hanno P, Parsons CL, et al. Pentosan polysulfate sodium for therapy of interstitial cystitis. A double-blind placebo-controlled clinical study. Urology 1990; 35: 552-558.

41 Parsons CL, Benson G, Childs SJ, et al. A quantitatively controlled method to study prospectively interstitial cystitis and demonstrate the efficacy of pentosanpolysulfate. J Urol 1993; 150: 845-848.

42 Chew D, Bartges J, Adams L, et al. Randomized, placebocontrolled clinical trial of pentosan polysulfate sodium for treatment of feline interstitial (idiopathic) cystitis. J Vet Intern Med 2009; 23: 690.

43 Francis BJ, Wells RJ, Rao S, et al. Retrospective study to characterize post-obstructive diuresis in cats with urethral obstruction. J Feline Med Surg 2010; 12: 606-608.

44 Hugonnard M, Chalvet-Monfray K, Dernis J, et al. Occurrence of bacteriuria in $\mathbf{1 8}$ catheterised cats with obstructive lower urinary tract disease: a pilot study. J Feline Med Surg 2013; 15: 843-848.

45 Eisenberg BW, Waldrop JE, Allen SE, et al. Evaluation of risk factors associated with recurrent obstruction in cats treated medically for urethral obstruction. J Am Vet Med Assoc 2013; 243: 1140-1146. 